\title{
Shear-induced crystallization of PB-1 up to processing-relevant shear rates
}

\author{
Chitiur Hadinata • Claus Gabriel • \\ Maximilian Ruellmann • Nhol Kao • \\ Hans Martin Laun
}

Published online: 5 September 2006

(C) Springer-Verlag 2006

The online version of the original article can be found at http://dx.doi. org/10.1007/s00397-005-0057-z of the article with published errors.

The paper was presented at AERC 2005, Grenoble, with the title "Shear-induced crystallization of polybutene-1 covering a wide shear rate range."

C. Hadinata $(\bowtie) \cdot$ N. Kao

School of Civil and Chemical Engineering, RMIT University,

Melbourne, Australia

e-mail: s9712858@student.rmit.edu.au

C. Gabriel $\cdot$ M. Ruellmann $\cdot$ H. M. Laun

BASF Aktiengesellschaft, Polymer Physics,

Ludwigshafen am Rhein, Germany
Unfortunately, Fig. 8 was published twice. This is the correct Fig. 7.

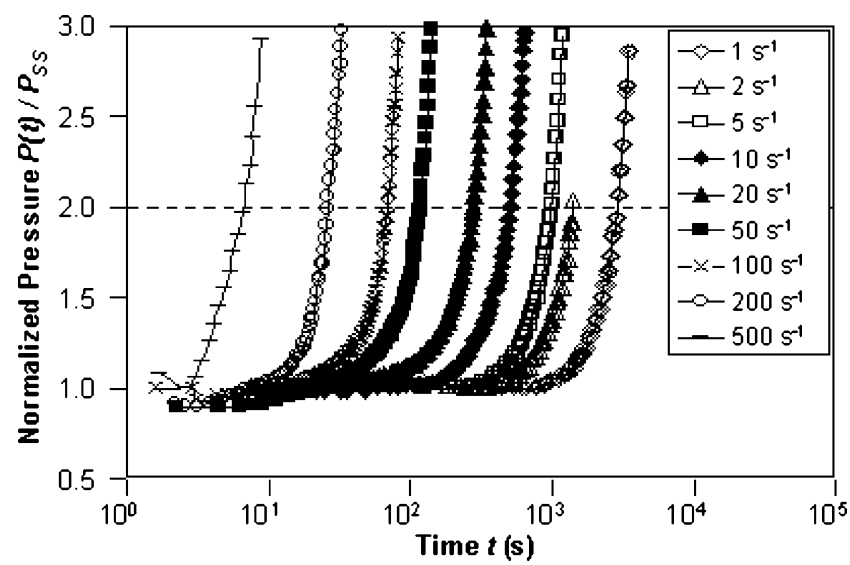

Fig. 7 Development of pressure signal in capillary rheometer during shear-induced crystallization runs for PB0400 at $107^{\circ} \mathrm{C}$, using shear rates $1-500 \mathrm{~s}^{-1}$ 